\title{
Effectiveness of auriculotherapy on anxiety during labor: did the authors switch outcomes or salami slice their trial?
}

\author{
Richard Gray ${ }^{1}$ \\ (D) https://orcid.org/0000-0001-9694-4206 \\ Bridgina Mackay ${ }^{1}$ \\ (D) https://orcid.org/0000-0003-1960-3453 \\ Amanda Waters ${ }^{1}$ \\ (1) https://orcid.org/0000-0002-3473-9327 \\ Ellie Brown ${ }^{2}$ \\ (D) https://orcid.org/0000-0002-1645-5443
}

\begin{abstract}
Letter to the Editor regarding the article "Mafetoni RR, Rodrigues MH, Jacob LMS, Shimo AKK. Effectiveness of auriculotherapy on anxiety during labor: a randomized clinical trial. Rev. Latino-Am. Enfermagem. 2018;26:e3030. DOI: http://dx.doi.org/10.1590/1518-8345.2471.3030."
\end{abstract}

Dear editors, we read with interest the paper published in Revista Latino-Americana de Enfermagem (RLAE) reporting the findings of a randomised controlled trial testing the effectiveness of auriculotherapy on anxiety ${ }^{(1)}$. We are writing to seek clarification from the study authors about the reporting of trial outcomes.

The trial by Mafetoni, et al.(1) was prospectively registered with the Brazilian Registry of Clinical Trials before the trial first participant was

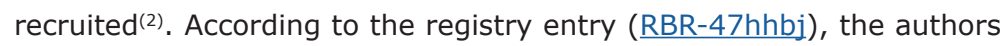
aimed to recruit 99 women in labor, and the primary outcome was pain determined using a 0-10 visual analogue scale. However, as far as we can determine, pain data are not reported in this manuscript. The apparent discrepancy between registry entry and manuscript is concerning and may be indicative of selective outcome reporting where the registered primary outcome is changed or omitted - by the authors $^{(3)}$. The primary purposes of trial registration is to eliminate outcome switching because of the potential for this practice to distort the evidence base ${ }^{(4)}$. However, it requires that reviewers and editors reconcile what the authors have stated in the registry entry with what they report in the manuscript. Alternatively, the omission of pain data from the paper may be indicative of an intent to report outcomes across multiple papers. We investigated this possibility by reviewing the first authors SCOPUS entry (author ID "Mafetoni, Reginaldo Roque" 56560075300). According to SCOPUS, Mafetoni has published five papers, all reporting results from auriculotherapy trials. We checked the trial registration numbers reported in the five manuscripts. Three papers related to the trial registration reference $\mathrm{RBR}-47 \mathrm{hhbj}^{(1,5-6)}$. The first paper $^{(6)}$ reports what are described as preliminary data from a

\section{How to cite this article}

Gray R, Mackay B, Waters A, Brown E. Effectiveness of auriculotherapy on anxiety during labor: did the authors switch outcomes or salami slice their trial? Rev. Latino-Am. Enfermagem. 2020;28:e3381. [Access in: DOI: http://dx.doi.org/10.1590/1518-8345.4697.3381. 
three-arm (auriculotherapy, placebo, control) double-blind trial. Results from 30 participants (10 in each trial arm) are presented. The authors conclude that participants in the auriculotherapy group tended greater pain control. The authors also state that the "trial precedes a larger study in progress" [sic] ${ }^{(6)}$. The second manuscript ${ }^{(1)}$ is the trial published in RLAE that reports the effectiveness of auriculotherapy against anxiety in a triple-blind, three-arm, RCT involving 102 participants. It is unclear if the subjects in the first paper(6) are part of 102 participants included in the second paper ${ }^{(1)}$. We wrote to the corresponding author on the $18^{\text {th }}$ June 2020 seeking clarification (they had not responded as of the $13^{\text {th }}$ July 2020). The authors report the effects of auriculotherapy against pain in a third paper(5). Again, the trial is described as triple-blind and involved 102 participants. The authors conclude that auriculotherapy is an effective treatment in women in labor. Reporting of the results of a single study across multiple manuscripts - typically described as salami slicing(7) - is a questionable research practice because of the potential to distort the evidence (for example, because papers from a single trial get included multiple times in systematic reviews). We would welcome an explanation from the authors about their approach to reporting their findings. It would also be informative if editors can check if reviewers or handling editor reconciled the submitted manuscript with the registry entry. If this was not done, can the editors explain why not?

\section{References}

1. Mafetoni RR, Rodrigues MH, Jacob LMS, Shimo AKK. Effectiveness of auriculotherapy on anxiety during labor: a randomized clinical trial. Rev. Latino-Am. Enfermagem [Internet]. 2018 Sep 6 [cited Jun 16, 2020];26(0). Available from: http://www.scielo.br/scielo.php?script=sci_arttext\&pid=S0104-11692018000100347\&lng=en\&tIng=en

2. Gray R, Gray G, Brown E. A review of prospective registration of trials published in nursing science journals in 2017. J Adv Nurs. 2019;75(12):3263-71.

3. Hutton JL, Williamson PR. Bias in meta-analysis due to outcome variable selection within studies. J R Stat Soc Ser C Appl Stat. 2000;49(3):359-70.

4. Chan A-W, Hróbjartsson A, Haahr MT, Gøtzsche PC, Altman DG. Empirical Evidence for Selective Reporting of Outcomes in Randomized Trials: Comparison of Protocols to Published Articles. JAMA. 2004 May 26;291(20):245765.

5. Mafetoni RR, Rodrigues MH, Silva FMB, Jacob LMS, Shimo AKK. Effectiveness of auricular therapy on labor pain: a randomized clinical trial. Texto Contexto Enferm. [Internet]. 2019 [cited Jun 16, 2020];28. Available from: http:// www.scielo.br/scielo.php?script=sci_arttext\&pid=S0104-07072019000100367\&tlng=en

6. Mafetoni RR, Shimo AKK. Effects of auriculotherapy on labour pain: a randomized clinical trial. Rev Esc Enferm USP. 2016 Oct;50(5):726-32.

7. Gray R, Baker C. Salami slicing. J Psychiatr Ment Health Nurs. [Internet]. 2016 Sep [cited Sep 20, 2016]; Available from: http://doi.wiley.com/10.1111/jpm.12290

Response of the authors of the article "Mafetoni RR, Rodrigues MH, Jacob LMS, Shimo AKK. Effectiveness of auriculotherapy on anxiety during labor: a randomized clinical trial. Rev. LatinoAm. Enfermagem. 2018;26:e3030. DOI: http://dx.doi.org/10.1590/1518-8345.2471.3030."

Dear Researchers, we appreciate the interest in our publication and the request for clarifications, which we received with great esteem and consideration.

The article "Effectiveness of auriculotherapy on anxiety during labor"(1) is part of a larger study that is a doctoral thesis called "Effects of auriculotherapy on labor", registry entry: RBR-47hhbj, of January 7, 2015, last updated on June 7, 2015. The study was approved by the local Research Ethics Committee (n. 855.496/CAAE: 35671514.6.0000.5404). A pilot study with 30 participants was previously conducted, from April to June 2015, to validate the data collection instrument and identify possible corrections to the study. Primary data on labor pain [visual analog scale (VAS) graded from 0 to 10] were taken from the pilot study for publication ${ }^{(2)}$. In the pilot study, blinding was considered for the participants and for the evaluators that collected the data, however, this was not performed, being later corrected in other publications through triple-blinding. The other data and other outcomes studied in the pilot study: anxiety (Hamilton Anxiety Rating Scale - HAM-A), time of labor and type of delivery, were recorded in a database.

The sample size was estimated at 99 participants. There were no changes to the variables or to the other characteristics studied in the pilot, therefore the complete data of the first 30 participants were included in the final analysis, giving a total of 102 participants (three more, predicting losses) in June 2016. 
Therefore, in order to allow a specific analysis of the outcomes and broad discussion with the literature, at the end of the study, the primary outcomes: labor pain ${ }^{(3)}$ and anxiety ${ }^{(1)}$, and the secondary outcomes: time of labor and type of delivery ${ }^{(4)}$ were included in different publications, although reported in the main study (RBR-47hhbj).

Best regards,

The authors.

\section{References}

1. Mafetoni RR, Rodrigues MH, Jacob LMS, Shimo AKK. Effectiveness of auriculotherapy on anxiety during labor: a randomised clinical trial. Rev. Latino-Am. Enfermagem. 2018;26. doi: https://doi.org/10.1590/1518-8345.2471.3030 2. Mafetoni RR, Shimo AKK. Effects of auriculotherapy on labour pain: a randomised clinical trial. Rev Esc Enferm USP. 2016;50(5):726-32. doi: https://doi.org/10.1590/s0080-623420160000600003

3. Mafetoni RR, Rodrigues MH, Silva FMB, Jacob LMS, Shimo AKK. Effectiveness of auticular therapy on labor pain: a randomised clinical trial. Texto Contexto Enferm. 2019;28. doi: https://doi.org/10.1590/1980-265x-tce-2018-0110 4. Mafetoni RR, Jacob LMS, Jorge HMF, Shimo AKK. Effects of auriculotherapy on labor time and cesarean section rate: randomized clinical trial. Rev Mineira Enferm. 2018;22:e-1139. doi: http://www.dx.doi.org/10.5935/14152762.20180069

Also, access the editorial "Commitment to integrity and transparency in research", DOI: http://dx.doi.org/10.1590/1518-8345.0000.3403. 